\title{
Characterization, XPS and Toxicological Study of Organothallium (III) Compounds with Schiff Base Ligands
}

\author{
Gyanendra Kumar Gaur $^{1 *}$, Shekhar Srivastava ${ }^{2}$ \\ ${ }^{1}$ Scientific Officer, Forensic Science Laboratory, Gwalior, India \\ ${ }^{2}$ Reader in Chemistry, University of Allahabad, Allahabad, India \\ Email: "ggaur9495@gmail.com
}

Received October 23, 2012; revised November 21, 2012; accepted November 29, 2012

\begin{abstract}
Many Organothallium Compounds have been used in medicine, industry and antibacterial activity. Optical properties are among the most fascinating and useful properties of many complexes and have been extensively studied using a variety of optical spectroscopic techniques. A basic understanding of the optical properties and related spectroscopic techniques is essential for characterization about semiconductors, insulators or metal. Optical properties are related to other properties and functionalities (e.g. electronic, magnetic, and thermal) that are of fundamental importance to many technological applications, such as energy conversion, chemical analysis, biomedicine, opto-electronics, communication, and radiation detection. The fundamental importance of Thallium is the ability to accept electrons due to empty d-orbitals and thus establish additional bonds ( $\sigma$ bond and $\pi$ bond) in chemistry. The Thallium metal, which has outer electronic configuration $6 \mathrm{~s}^{2}, 6 \mathrm{p} 1$ shows oxidation states of Thallium (III) and Thallium (I). This research paper explains that Thallium (III) and Thallium (I) accepts lone pairs from various bi-dentate tetra-dentate Schiff base ligands due to p-orbital and vacant d-orbital. This research paper explains the Characterization, XPS and Toxicological Study of Organothallium (III) Compounds with Schiff base ligands by physiochemical technique. X-Ray photoelectron spectrography (XPS) study of Thallium (III) complexes with Schiff Base ligands also reported in this paper. XPS study shows a single symmetrical peak without any splitting in photoelectron peak, which confirms diamagnetic nature of all prepared molecular adducts. All prepared complexes with Schiff base ligands show toxicological effect.
\end{abstract}

Keywords: Oxidation; Ligand; Diamagnetic; Organothallium Compound; Molecular Adducts

\section{Introduction}

The organometallic chemistry has developed rapidly in III-B group of metals like gallium, indium and thallium during few years. The organometallic compounds of these metals have found useful applications in the production of metal carbonyls [1], metal cyclo-pentadiencyls [2-4] and ultra pure metals $[5,6]$. Some important applications of organometallic compounds of the metals are used as lubricants [7], antiknock reagents [8] and polymerization catalysts for olefins [9-11]. Poisoned food technique and Toxicological study has been recently employed to determine the fungicidal activity of these compounds. Preliminary evaluation of biocidal activity of some compounds against tomato seedlings has indicated that organometallic compounds of these metals are potential fungicides [12].

\section{Experimental Details}

The physicochemical technique was used for synthesized

${ }^{*}$ Corresponding author. organothallium (III) in present work. The elemental analysis was determined on a semimicro scale at Central Drug Research Institute, Lucknow, India. Molar conductance of all complexes was measured at room temperature in Acetone by Digisun Electronics Conductivity Bridge. The X-ray photoelectron spectra (XPS) were recorded by VG Scientific ESCA-3MK II electron spectrometer at National Chemical Laboratory, Poona-6. The $\mathrm{MgK}_{\alpha} \mathrm{X}$-ray line $(1253.6 \mathrm{eV})$ was used for photo excitation. The $\mathrm{Cu}_{2} \mathrm{p}_{3 / 2}($ B.E. $=932.8 \pm 0.2 \mathrm{eV})$ and $\mathrm{Au}_{4} \mathrm{f}_{7 / 2}$ (B.E. $=368.2 \mathrm{eV}$ ) was used for cross-checking. All the spectra were recorded using the same spectrometer parameters of $50 \mathrm{eV}$ pass energy and $4 \mathrm{~mm}$ slit width. The reduced full width at half maximum (FWHM) at the $\mathrm{Au}_{4} \mathrm{f}_{7 / 2}($ B.E. $=83.8 \mathrm{eV})$ level under these conditions was $1.2 \mathrm{eV}[13]$.

\section{Chemical Analysis}

The powdered sample was mixed with high purity silver powder to reduce the charging effect. A thin layer of such a sample was pressed on a gold metal gauge which 
was welded to nickel sample holder. The $\mathrm{Ag}_{3} \mathrm{~d}_{5 / 2}$ level $(\mathrm{BE}=368.2 \mathrm{eV})$ obtained which was sharp and did not show any observable shift. Thus, the charging of the sample was negligible. The spectra were recorded in triplicate in the region. In different cases the binding energies were reproducible within $\pm 0.1 \mathrm{eV}$.

The physicochemical technique was used for preparation of hydrated Thallium (III) Chloride $\left(\mathrm{TlCl}_{3} \cdot 4 \mathrm{H}_{2} \mathrm{O}\right)$. Thallium Chloride $(\mathrm{TlCl})$ was obtained from reacting Thallium Methal with $\mathrm{HCl}$ in 1:1 molar ratio in the presence of $\mathrm{HNO}_{3}$ and $\mathrm{H}_{2} \mathrm{SO}_{4}$. Hydrated Thallium (III) Chloride was obtained by passing a current of Chloride through an aqueous suspension of Thallium (I) Chloride till a clear solution was obtained. The solution was then concentrated in a current of Chloride at $60^{\circ}$ and cooled in a freezing mixture and salt to yield colorless plates of Tetra-hydrated Thallium (III) Chloride $\left(\mathrm{TlCl}_{3} \cdot 4 \mathrm{H}_{2} \mathrm{O}\right)$.

Phenyl Thallium Chloride $\left(\mathrm{PhTlCl}_{2}\right)$ has been prepared by the reaction of Thallic Chloride with Phenylboric acid in water. It has been recrystallised from water [14]. Phenylboric acid was obtained from phenyl magnesium bromide and n-butylborate in ether [15]. Among the organmetallics of the III (B) group of elements, those of the general formula $\mathrm{RMX}_{2}$ (where $\mathrm{R}=\mathrm{Ph}, \mathrm{X}=\mathrm{Cl}$ ) have received considerable attention of the workers due to their significantly high thermal stability.

$\mathrm{RMX}_{2}$ (where $\mathrm{R}=$ Phenyl, $\mathrm{M}=\mathrm{Tl}$, and $\mathrm{X}=\mathrm{Cl}$ ) have $\mathrm{sp}^{2}$ hybridization with one vacant $\mathrm{p}$-orbital and five d-orbital. These vacant orbital can accept lone pair from various donors and form molecular adducts of the type $\mathrm{RMX}_{2} \mathrm{D} ; \mathrm{RMX}_{2} \mathrm{~L}$ where $(\mathrm{D}=$ monodenate donor; $\mathrm{L}=$ bidenate donor). Many $\mathrm{PhTlCl}_{2}$ complexes with bidenate Schiff base ligands have been synthesized and characterized by physicochemical technique. Table 1 shows the analytical data of Phenyl Thallium Chloride $\left(\mathrm{PhTlCl}_{2}\right.$ $\mathrm{SB})$.

Table 1. Analytical data of Phenyl Thallium Chloride $\left(\mathrm{PhTlCl}_{2} \cdot \mathrm{SB}\right)$.

\begin{tabular}{|c|c|c|c|c|c|c|}
\hline \multirow[t]{2}{*}{ S.No. } & \multirow[t]{2}{*}{ Complex } & \multicolumn{4}{|c|}{$\%$ Found (calculated) } & \multirow{2}{*}{$\begin{array}{c}\text { Molar } \\
\text { conductance in } \\
\text { acetone } \\
\left(\mathrm{ohm}^{-1} \mathrm{~cm}^{2}\right. \\
\left.\mathrm{mol}^{-1}\right) \\
\end{array}$} \\
\hline & & $\mathrm{Tl}$ & $\mathrm{C}$ & $\mathrm{H}$ & $\mathrm{N}$ & \\
\hline 1. & $\mathrm{PhTlCl}_{2} \mathrm{SB}_{13}$ & $\begin{array}{c}31.6 \\
(31.77)\end{array}$ & $\begin{array}{c}44.4 \\
(44.85)\end{array}$ & $\begin{array}{c}3.4 \\
(3.58)\end{array}$ & $\begin{array}{c}8.3 \\
(8.72)\end{array}$ & 25 \\
\hline 2. & $\mathrm{PhTlCl}_{2} \mathrm{SB}_{14}$ & $\begin{array}{c}34.4 \\
(34.45)\end{array}$ & $\begin{array}{c}40.4 \\
(40.54)\end{array}$ & $\begin{array}{c}3.2 \\
(3.34)\end{array}$ & $\begin{array}{c}9.2 \\
(9.45)\end{array}$ & 26 \\
\hline 3. & $\mathrm{PhTlCl}_{2} \mathrm{SB}_{15}$ & $\begin{array}{c}33.2 \\
(33.22)\end{array}$ & $\begin{array}{c}42.6 \\
(42.99)\end{array}$ & $\begin{array}{c}3.1 \\
(3.09)\end{array}$ & $\begin{array}{c}9.0 \\
(9.12)\end{array}$ & 28 \\
\hline 4. & $\mathrm{PhTlCl}_{2} \mathrm{SB}_{16}$ & $\begin{array}{c}36.0 \\
(36.17)\end{array}$ & $\begin{array}{c}38.1 \\
(38.29)\end{array}$ & $\begin{array}{c}3.0 \\
(3.01)\end{array}$ & $\begin{array}{c}9.5 \\
(9.92)\end{array}$ & 30 \\
\hline 5. & $\mathrm{PhTlCl}_{2} \mathrm{SB}_{17}$ & $\begin{array}{c}31.4 \\
(31.92)\end{array}$ & $\begin{array}{c}45.0 \\
(45.07)\end{array}$ & $\begin{array}{c}3.0 \\
(3.12)\end{array}$ & $\begin{array}{c}8.6 \\
(8.76)\end{array}$ & 22 \\
\hline
\end{tabular}

\section{Results and Discussion}

The complex of Organothellium (III) with bidenate Schiff base ligands and molecular adducts have been synthesized and characterized by the interaction of $\mathrm{PhTlCl}_{2}$ in Chloroform. It is clear from Table 1 that these complexes were stable towards atmospheric oxygen, moisture and at room temperature on long time. Molar conductance of $10^{-3} \mathrm{M}$ solution of the complexes was determined at room temperature. Figure 1 shows the geometrical structure of $\mathrm{PhTlCl}_{2}$ with schiff base ligands which confirmed their stability. It is observed that the absence of Ionic species in the range of $20 \mathrm{ohm}^{-1} \mathrm{~cm}^{2} \mathrm{~mol}^{-1}$ to 30 $\mathrm{ohm}^{-1} \mathrm{~cm}^{2} \mathrm{~mol}^{-1}$ in acetone. All the molecular adducts exhibit the $\mathrm{C}=\mathrm{N}$ absorption around $1620 \mathrm{~cm}^{-1}$ to $1610 \mathrm{~cm}^{-1}$ which normally appears at $1640 \mathrm{~cm}^{-1}$ in the free ligands. The lowering of this band in the complexes indicates the coordination of nitrogen atoms of Azomethine group to the Thallium (II) and Thallium (III). Figure 2 shows the $\mathrm{N} 1 \mathrm{~s}$ photoelectron peak and binding energy $(\mathrm{eV})$ of $\mathrm{PhTlCl}_{2}$ with Schiff base ligands. It is observed that the $\mathrm{PhTlCl}_{2} \cdot \mathrm{SB}$ shows Tl4f, N1s and 01s photoelectron peak from X-ray photoelectron spectra (XPS) study. XPS study shows that the binding energy increases as well as the electron density on Thallium metal ion by coordination of Schiff base ligands with Thallium metal ion.

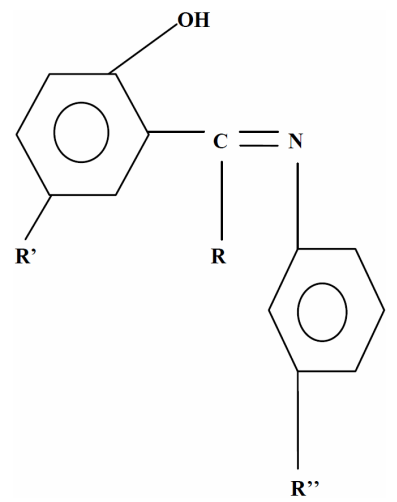

Figure 1. The Geometrical structure of $\mathrm{PhTICl}_{2}$ with Schiff base ligands.

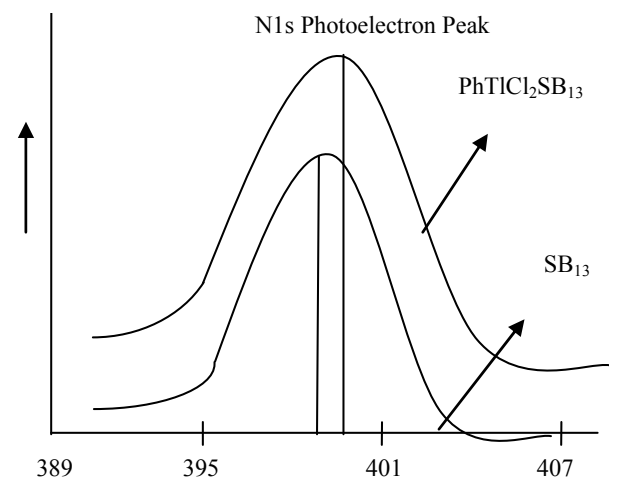

Figure 2. N1s photoelectron peak and binding energy (eV) of $\mathrm{PhTlCl}_{2}$ with Schiff base ligands. 


\section{Conclusion}

It is clear that the photoelectron peaks towards higher binding energy side due to $\mathrm{L} \rightarrow \mathrm{M}$ charge transfer from XPS Study. All prepared complexes are stable under atmospheric conditions at room temperature and it is confirmed through their geometrical structure. XPS study shows a single symmetrical peak without any splitting in photoelectron peak, which confirms diamagnetic nature of all prepared molecular adducts. Toxicological study of these complexes found very prominent.

\section{Acknowledgements}

I am thankful to the Central Drug Research Institute, Lucknow, India for elemental analysis of Thallium (III) and National Chemical Laboratory, Poona-6 for X-ray photoelectron spectra (XPS).

\section{REFERENCES}

[1] H. E. Podall and H. Shapire, "The Organmetallic Chemistry of the Transition Metals," Wiley, Chichester, 1960.

[2] C. C. Hant and J. R. Doyle, "Synthesis of Cyclopentadienide Derivatives," Inorganic and Nuclear Chemistry Letters, Vol. 2, No. 10, 1966, pp. 283-288. doi:10.1016/0020-1650(66)80043-0

[3] A. N. Nesmeyanov, R. B. Materikova, N. S. Kochetkova and R. V. Luk'yanova, "Preparation of Diphenylnickel with Cyclopentadienylthallium," Bulletin of the Academy of Sciences of the USSR, Division of Chemical Science, Vol. 18, No. 4, 1969, p. 896.

[4] R. B. King and M. B. Bisnette, "Initial Examples of the Synthesis of Cp*-Metal Complexes," Journal of Organometallic Chemistry, Vol. 8, 1967, pp. 287-297.

[5] C. Seamus, X. G. Ji, I. C. Douqlas and P. Michael, "Process for the Production of Ultra Pure Metals from Oxide and Their Cold Rolling to Ultra Thin Foils for Use as Particle Accelerator Targets and Reference Materials," Special Issue of Nuclear Instruments and Methods in Physics
Research, 2000

http://publications.jrc.ec.europa.eu/repository/handle/111 111111/11716

[6] R. Detzer, "Hochreine Metalle Durch Elektroraffination in Metallorganischen Komplexsalzschmelzen," Chemie Ingenieur Technik, Vol. 36, No. 6, 1964, pp. 616-637. doi:10.1002/cite.330360606

[7] M. Antler, "Materials, Coatings and Platings, in Electrical Contacts: Principles and Applications," Marcel Dekker, New York, 1999.

[8] S. Samson and G. R. Stephenson, "Pentacarbonyliron," In: L. Paquette, Ed., Encyclopedia of Reagents for Organic Synthesis, John Wiley \& Sons, New York, 2004.

[9] R. Hoff and R. T. Mathers, "Handbook of Transition Metal Polymerization Catalysts," John Wiley \& Sons, New York, 2010.

[10] G. J. P. Britovsek, V. C. Gibson and D. F. Wass, "The Search for New-Generation Olefin Polymerization Catalysts: Life beyond Metallocenes," Angewandte Chemie International Edition, Vol. 38, No. 4, 1999, pp. 428-447. doi:10.1002/(SICI)1521-3773(19990215)38:4<428::AIDANIE428>3.0.CO;2-3

[11] M. Bochmann and I. Organometallics, "Complexes with Transition Metal-Carbon $\sigma$-Bonds," Oxford University Press, New York, 1994.

[12] T. N. Srivastava and K. K. Bajpai, Journal of Organometallic Chemistry, Vol. 31, No. 1, 1971, pp. 1-3. doi:10.1016/s0022-328x(00)87457-4

[13] S. Srivastava, "ESCA Studies of Metal Complexes," Applied Spectroscopy Reviews, Vol. 22, No. 4, 1986, pp. 401-535. doi:10.1080/05704928608060441

[14] F. Challenger and B. Parker, "CXCIX-A Method for the Preparation of Some New Organo-Thallium Halides," Journal of the Chemical Society, 1931, pp. 1462-1467. doi:10.1039/jr9310001462

[15] F. R. Bean and J. R. Johnson, "Derivatives of Phenylboric Acid, Their Preparation and Action upon Bacteria. II. Hydroxyphenylboric Acids," Journal of the Chemical Society, Vol. 54, No. 11, 1932, pp. 4415-4425. doi: $10.1021 / \mathrm{ja} 01350 \mathrm{a} 045$ 